\title{
Indirect costs of cervical and breast cancers in Spain
}

B reast cancer is the tumor with the highest prevalence rate in women in industrialized countries and the second most frequent cause of death in women in Spain after coronary disease. In the year 2000 breast cancer caused 5,663 deaths. The incidence of breast cancer increases after the age of 40 years, although most of the deaths are in patients aged over $65(62 \%)$ [12]. Nevertheless the survival rate at 5 years in Spain ranges from $69 \%$ to $72 \%$ [23] due to early diagnosis and advances in therapy. In Spain cervical cancer caused 594 deaths in the year 2000, 313 in women under aged 65 (nearly 53\%). The aetarian groups most affected by cervical cancer range are those aged 45-64 years, and the survival rate at 5 years is about $58-66 \%$.

The incidence of both types of cancer has increased in Spain during recent decades but is still lower than in North America and in other western European countries but is higher than in Eastern Europe, Asia, and Africa [28]. Both types of cancer are related to genetic predisposition, hormonal state, and anthropometric features but are also influenced by life-style (diet, sedentarism, smoking and drinking habits, reproductive factors) and by cultural and environmental factors $[17,35]$.

Breast and cervical cancers are a priority for Spanish health authorities because of their importance and the availability of effective preventive interventions that reduce their incidence (e.g., see $[3,4,9,20,24]$ ). The Spanish Ministry of Health has recently included the assessment of cost of illness in the research studies that it promotes to evaluate the overall impact of diseases [29].

Resources should not be allocated on the basis of disease costs but according to the benefits of intervention [30]. Studies estimating disease costs can, however, help in illustrating the actual magnitude of health problems. Cost-of-illness studies are useful for quantifying the opportunity costs of resources devoted to health care, and other purposes, and the loss in production, because of ill health. They also offer valuable information to the authorities and society at large about the relative and absolute impact of health problems, therefore helping in the establishment of priorities. For instance, costs of preventive treatments can be compared to costs of inadequate treatment, or to costs arising from absence of treatment.

The scientific literature offers only a few studies dealing with indirect costs of cancer. Most of these studies follow the human capital (HC) approach, with indirect costs covering a substantial part of total costs $[1,23,27,34]$. An alternative method is known as the friction costs (FC) approach. The methodological discussion about the relative advantages and disadvantages of these perspectives is continuing. The two approaches reach very dif- ferent results, with lower values in the FC method. Koopmanschap et al. [19] found significant differences between them. Further studies following both $\mathrm{HC}$ and FC points of view have assessed the costs of migraine [22], mental illness [25], coronary diseases [23, 31], cancer [23], and back and neck pain $[5,11]$.

The aim of the present study was to contribute to the debate on HC and FC methods and to offer relevant information to the health decision maker for estimating indirect costs associated with annual morbidity and mortality caused by cervical and breast cancers in Spain by using the two alternative perspectives.

\section{Methods}

\section{Definition of "indirect cost"}

The concept of indirect cost is still under discussion in the field of economic evaluation. Two fundamental questions - "what does indirect cost mean and "how should indirect cost be evaluated" - remain answered

Table 1

Distribution by age of the number of women dead due to breast and cervical cancers in Spain for the year $\mathbf{2 0 0 0}$ (from Spanish Deaths Registry and our own elaboration)

\begin{tabular}{|lrc|}
\hline Age (years) & Breast cancer & Cervical cancer \\
\hline $0-24$ & 5 & 0 \\
\hline $25-44$ & 447 & 101 \\
\hline $45-64$ & 1,707 & 212 \\
\hline $65-74$ & 1,359 & 127 \\
\hline $75+$ & 2,145 & 154 \\
\hline Total & 5,663 & 594 \\
\hline
\end{tabular}


in various ways. A wider interpretation of indirect costs adds up the complete time loss due to illness [6]. However, the most common definition for indirect cost is restricted to the loss of labor productivity due to ill health. The present study estimates annual labor productivity loss, distinguishing between costs stemming from early mortality and costs stemming from morbidity (temporary and permanent disability).

The HC approach has been the most commonly used method for measuring and evaluating productivity loss $[10,26$, 33]. This method assumes that when a worker leaves the labor market, his/her labor productivity is lost until the worker returns to work, in the case of temporary disability, or until the end of his/her working life, in the case of permanent disability. Wages provide a reasonable measure for assessing labor factor productivity [2, $7,8]$. The HC approach has a strong economic tradition and takes a social perspective, relying on accounted and available data. However, from a theoretical point of view the $\mathrm{HC}$ method has been criticized, arguing the superiority of contingent valuation methods (willingness to pay in order to avoid illness-related problems). The practical use of these methods, however, also presents problems [32].

An alternative is the FC method [18]. The main idea here is that workers with temporary disability can make up for lost work when they return to work; coworkers can replace them in urgent tasks, and non urgent tasks can be canceled. In the case of permanent disability or early mortality the worker would be replaced by another person from the unemployed pool, filling the vacant position. In the FC model productivity loss due to temporary disability is lower than in the HC approach. In a long-term perspective, after an adjustment or "friction period," production loss would be zero. This approach presumes that individual production lost by a sick worker is not comparable to production loss from a social point of view because an unused resource fills the gap (the replacement worker).

Differences between costs estimations using HC vs. FC depend on three basic elements: labor flexibility (the capability of delaying and/or canceling non urgent tasks and of performing the most urgent ones), unemployment rate, and length of time with "friction costs." The higher the flexibility and the unemployment rate, the greater is the difference between the respective estimates. The shorter the friction period, the greater is the difference.

\section{Data}

Data on deaths caused by breast and cervical cancers were obtained from the Spanish Registry of Deaths by cause [12]. This data source gives yearly information about deaths by basic cause according to the International Classification of Diseases (ICD). The basic cause of death is defined as the disease or injury that started the chain of pathological events driving directly to the death or the circumstances of the accident or violence that produced the deadly injury. ICD codes 174,175 , and 180, clinical modification (ICD-9-CM), were used to identify deaths directly attributable to breast and cervical cancers. The data correspond to year 2000, the latest available at the time of the study. We assume that data have not significantly changed since then.

The number of persons with permanent disability was obtained from a study conducted by the Spanish Institute of the Social Security (M.D. Carbajo-Sotillo et al., personal communication, 2003) relying upon a statistically significant random sample of 1,757 cases of permanent disability for the year 2001 . To extrapolate these figures to the national level we used data on early retirements due to permanent disability (from the same Institute). Data on temporary disability were obtained from statistics concerning the Canary Islands (population 1.78 million in 2001, compared to the Spanish population of $42 \mathrm{mil}-$ lion; INE: http://www.ine.es/inebase/menu1. $\mathrm{htm} \# 5$ ) and were extrapolated to the national total figures, controlled by the size of the labor markets and the epidemiological variability in this region, with respect to the Spanish labor market and the national epidemiological results. Labor production lost is estimated by female gross wages. Female wages were obtained from the Industry and Services Wages Survey [13]. Female employment rates by age were obtained from the Active Population Survey [14]. Costs were updated to the year 2003 .

\section{Estimation methods}

Regarding deaths were estimated years of potential life lost (YPLL) and years of po-

Table 2

Distribution by age of the Years of Potential Life Lost (YPLL) caused by premature mortality of breast and cervical cancers in Spain for the year 2000 (from Spanish Deaths Registry and our own elaboration)

\begin{tabular}{lcc} 
Age (years) & Breast cancer & Cervical cancer \\
\hline 0 & 235 & 0 \\
\hline 25 & 13,414 & 3,057 \\
\hline 45 & 23,064 & 3,189 \\
\hline $65+$ & 1,312 & 136 \\
\hline Total & 38,025 & 6,382 \\
\hline
\end{tabular}

Table 3

Number of deaths in women aged under 65 years and the number of years of potential productive life lost (YPPLL) due to breast and cervical cancers in Spain for the year 2000 (from Spanish Deaths Registry and our own data)

\begin{tabular}{|lcc} 
& Breast cancer & Cervical cancer \\
\hline Deaths & 2,159 & 313 \\
\hline YPPLL & 28,077 & 4,994 \\
\hline
\end{tabular}


tential productive life lost (YPPLL) using a simple method due to the fact that the probabilities of mortality for women aged under than 65 years is minimal. For estimation of YPLL we followed the procedure of the Spanish National Statistics Institute (INE). This indicator shows the extent of mortality from a certain cause that could theoretically be avoided, considering the total number of life years lost due to premature death in a given population. YPLL was estimated for the age range 1-69.

The next step was to transform YPLL into YPPLL. For this we estimated the number of total deaths occurred at working age or before 16 years (age of entry into the labor market is 16). The age of exit from the labor market was considered to be the legal age of retirement, i.e., 65 years. This means that YPPLL is equal to zero for deaths occurring after age 65 . When estimating YPLL and YPPLL no discount rate was used. However, when estimating costs we did adjust data with the female employment rate (adjusted by age) and updated with the appropriate discount rate and annual productivity growth rate.

Costs due to early mortality were estimated as the present monetary value of the flow of production along time lost as a result of the death. The HC approach states that if persons had not died prematurely, they would have continued being productive for a certain number of years, until the age of retirement. These years were estimated as the difference between the legal age of retirement and the age of death. We consider deaths of girls and teenagers girls due to breast cancer (no deaths have been reported due to cervical cancer before the age of 24 years) because if disease prevention avoids death the person concerned would enter the labor market at the age of 16 . In this way every girl dying before the age of 16, represents 49 YPPLL (65 less 16 years).

Annual female wages lost due to breast and cervical cancers were adjusted by employment rates by age in every case of death. The adjustment is necessary because only a certain proportion of women of working age hold a paid job, and only in these cases should the loss of labor productivity be estimated (considering both employment rate and female gross wage the effect of higher female part-time employment is recorded). The adjusted wages are updated to the refer- ence year (2003). The base line case takes up zero for both discount rate and annual growth of labor productivity. Then the annual discount rate was changed between o-6\% and the annual growth rate for labor productivity between $0-3 \%$ as exercises in the sensitivity analysis.

To estimate FC our baseline case assumes that if permanent labor leaves (early mortality and permanent labor disability), the cost for the employer of finding and training a replacement is equivalent to the wage paid for the work performed in 2.5 months, or 75 days ("friction period"). This is counted for persons dying between the ages of 16 and 65 years [ 18 , 19] corrected by the Spanish female employment rates adjusted by age. For the sensitivity analysis we assessed costs over a longer "friction period" of 3.5 months (105 days).

Another component of indirect costs is permanent disability. Productivity loss is estimated in a way similar to the procedure followed for early mortality. There is no need for adjustment to employment rates by either methods ( $\mathrm{HC}$ and FC), as data refer to women in the labor market. We must, however, clarify an important point concerning costs due to permanent disability. Persons retiring from the labor market due to the tumors may die before the age of 65 . If we add up for the same individual production loss due to permanent disability and production loss due to early mortality, we would be committing double accounting. To avoid this the results are adjusted by using survival rates [23]. (In Spain permanent disability pensions are normally awarded after a period of 18 months out of work due to illness. If the period of labor inactivity is lower than 18 months, we consider it as a case of temporary disability.) Temporary disability is represented by the productivity lost when individuals cannot work for a certain period of time due to illness or disability. To ascertain these costs we used female wages and the number of working days lost for every employed individual. In the FC approach individual data are censored at a maximum of 75 days (105 in the sensitivity analysis). Since breast cancer affects almost exclusively females (more than $99 \%$ of cases), we omitted males when evaluating indirect costs.

\section{Juan Oliva · Félix Lobo \\ Julio López-Bastida · Néboa Zozaya \\ Rosa Romay \\ Indirect costs of cervical and breast cancers in Spain}

\begin{abstract}
This study estimated the indirect costs (productivity loss) caused by mortality and morbidity of cervical and breast cancers in Spain. We used two alternative methods: (a) the traditional human capital $(\mathrm{HC})$ approach and (b) the friction cost (FC) method. The annual costs were $€ 43.4$ and 288.7 for cervical and breast cancer, respectively, by the $\mathrm{HC}$ approach and $€ 1.1$ and 11.6 million by the FC approach. Cost-of-illness studies help to illustrate the real dimension of health problems and should be a major concern for health policies. Indirect costs are relevant information about diseases. However, the estimated indirect costs depend heavily on the approach adopted.
\end{abstract}

\section{Keywords}

Cancer - Indirect costs · Human capital .

Friction cost · Spain 
Indirect costs (euros) of breast and cervical cancers for the year 2003 (from our own data)

\begin{tabular}{|lcccc}
\hline & $\begin{array}{l}\text { Premature } \\
\text { mortality }\end{array}$ & $\begin{array}{l}\text { Permanent } \\
\text { disability }\end{array}$ & \multicolumn{1}{l}{$\begin{array}{l}\text { Temporary } \\
\text { disability }\end{array}$} & Total \\
\hline $\begin{array}{l}\text { HC method } \\
\text { - Breast cancer }\end{array}$ & $113,055,606$ & $159,295,201$ & $16,381,077$ & $288,731,884$ \\
- Cervical cancer & $21,701,097$ & $20,565,112$ & $1,161,016$ & $43,427,225$ \\
\hline $\begin{array}{l}\text { FC method } \\
\text { - Breast cancer }\end{array}$ & $2,287,455$ & $5,452,925$ & $3,880,586$ & $11,620,966$ \\
- Cervical cancer & 393,161 & 310,801 & 432,068 & $1,136,030$ \\
\hline $\begin{array}{l}\text { FC vs. HC } \\
\text { - Breast cancer }\end{array}$ & $2 \%$ & & & $4 \%$ \\
- Cervical cancer & $1.8 \%$ & $3.4 \%$ & $23.7 \%$ & $2.6 \%$ \\
\hline
\end{tabular}

Table 5

Sensitivity analysis of indirect costs (euros) of breast and cervical cancers estimated by the human capital approach for the year 2003 using different annual growth rates for labor productivity and annual discount rates (from our own data)

\begin{tabular}{|c|c|c|c|}
\hline & \multicolumn{3}{|c|}{ Annual discount rate } \\
\hline & $0 \%$ & $3 \%$ & $6 \%$ \\
\hline \multicolumn{4}{|l|}{$0 \%$ growth } \\
\hline - Breast cancer & $288,731,884$ & $256,757,516$ & $229,354,607$ \\
\hline - Cervcal cancer & $43,427,225$ & $35,020,197$ & $29,309,194$ \\
\hline \multicolumn{4}{|l|}{$1 \%$ growth } \\
\hline - Breast cancer & $308,509,276$ & $267,995,863$ & $238,104,452$ \\
\hline - Cervical cancer & $47,085,823$ & $37,503,121$ & $31,078,560$ \\
\hline \multicolumn{4}{|l|}{$2 \%$ growth } \\
\hline - Breast cancer & $325,002,957$ & $280,206,139$ & $247,521,069$ \\
\hline - Cervical cancer & $51,250,152$ & $40,289,566$ & $33,039,895$ \\
\hline
\end{tabular}

Table 6

Sensitivity analysis of indirect costs (euros) of breast and cervical cancers by the friction cost approach for the year 2003 and FC vs. HC results (1-3\% scenario)

\begin{tabular}{lrrrr} 
Type of tumor & $\begin{array}{l}\text { Premature } \\
\text { mortality }\end{array}$ & $\begin{array}{l}\text { Permanent } \\
\text { disability }\end{array}$ & $\begin{array}{l}\text { Temporary } \\
\text { disability }\end{array}$ & \multicolumn{1}{l}{ Total } \\
\hline $\begin{array}{l}\text { FC (2.5 months) } \\
\text { - Breast cancer }\end{array}$ & $2,287,455$ & $5,452,925$ & $3,880,586$ & $11,620,966$ \\
- Cervical cancer & 393,161 & 310,801 & 432,068 & $1,136,030$ \\
\hline $\begin{array}{l}\text { FC (3.5 months) } \\
\text { - Breast }\end{array}$ & $3,202,437$ & $7,634,095$ & $5,166,305$ & $16,002,837$ \\
- Cervical cancer & 550,425 & 435,122 & 531,624 & $1,517,171$ \\
\hline $\begin{array}{l}\text { FC (2.5-3.5 months) vs. HC } \\
\text { - Breast cancer }\end{array}$ & $(2.3-3.2 \%)$ & $(3.6-5.0 \%)$ & $(23.7-31.5 \%)$ & $(4.3-5.9 \%)$ \\
- Cervical cancer & $(2.1-2.9 \%)$ & $(1.8-2.5 \%)$ & $(37.2-45.8 \%)$ & $(3.0-4.0 \%)$ \\
\hline
\end{tabular}

\section{Results}

Breast cancer today affects a higher number of women and at a more advanced age than cervical cancer. $\bullet$ Table 1 shows that most deaths caused by both cancers $(62 \%)$ occurred after retirement age. YPLL due to breast cancer reached 38,025 and that due to cervical cancer 6,382 (• Table 2). The YPPLL figure is 28,077 for breast cancer and 4,994 for cervical cancer (• Table 3).

- Table 4 shows indirect costs caused by breast and cervical cancers in Spain according to the two approaches. In the baseline case annual discount rate an annual growth of labor productivity are $\mathrm{\%}$ (HC approach) and the "friction period" 2.5 months (FC approach). By the $\mathrm{HC}$ approach indirect costs associated with breast cancer reach $€ 288.7$ million and those associated with cervical cancer $€ 43.4$ million. By the FC approach the figures are $€ 11.6$ million and $€ 1.1$ million, respectively. In breast cancer the HC method gives permanent disability as the main cause of productivity loss, followed by early mortality. In cervical cancer indirect costs are similar for early mortality and permanent disability. This result can be explained by the higher survival rate of women suffering from breast cancer compared to cervical cancer. By the FC approach in cervical cancer indirect costs are similar in the three situations, temporary disability, permanent disability, and early mortality. Regarding breast cancer indirect costs caused by permanent disability are higher than the other two factors.

It is important to highlight the remarkable differences observed between the results obtained by the two perspectives. Indirect costs estimated by the FC approach are much lower than those estimated by the HC method. The difference depends on the cost item considered. The most important differences are found in costs caused by early mortality and permanent disability, where $\mathrm{FC}$ costs are in a range as low as $1.5-3.4 \%$ of $\mathrm{HC}$ costs. For temporary disability the costs by the FC approach range between $24 \%$ and $37 \%$ of indirect costs obtained by the $\mathrm{HC}$ approach.

The above results (• Table 4) are based on the assumption that the discount rate and the growth of labor productivity are zero, not a realistic hypotheses. To be more realistic in the sensitivity analysis we estimated the loss of labor productivity (HC) for different rates (see $\bullet$ Table 5 ). The sensitivity analysis for the FC approach (- Table 6) varies the friction period from 2.5 months (75 days) to 3.5 months (105 days). 0 Table 6 also shows how indirect costs change accordingly a more plausible scenario ( $1 \%$ annual growth 
rate for labor productivity and a $3 \%$ discount rate) with the results obtained by the FC method. As can be seen, the results of $\bullet$ Table 6 confirm the remarkable variations in the estimations of indirect costs depending on the methodology used. By the FC method the indirect costs are 4.3-5.8\% (breast cancer) and 3.0-4.0\% (cervical cancer) of those determined by the $\mathrm{HC}$ method.

\section{Conclusions}

Screening and treatment of breast and cervical cancers are two main priorities for Spanish health authorities. Together with epidemiological data and health care costs, indirect costs can help to reveal the socioeconomic impact of diseases. Our study follows the most common definition for indirect cost (loss of labor productivity due to ill health) using the two most common approaches, HC and FC. We observed sharp variations in the results depending on the method used. There is no doubt that indirect costs are a component of great importance and significance in the total costs of many diseases. However, the concept of indirect costs entails numerous unanswered methodological difficulties as well as such fundamental questions as "what does indirect cost mean" and "how should indirect cost be evaluated". There are several arguments and opinions about the best method for assessing indirect costs putting fuel to a heated debate. The HC approach estimates a potential loss of productivity. This method has been strongly criticized but it is based on economic theory, and some authors consider that it provides the lower limit of the willingness to pay for an individual to improve his/her health [16]. The FC method is an eclectic method that seeks realistic estimations of labor productivity loss but has been strongly criticized because of contradictions of economic theory $[15,21]$. A wider interpretation of the concept of indirect cost should include, ideally, other concepts, such as the product generated by housework or the leisure time sacrificed in order to approach the real loss of social welfare. However, information systems and national accounts are still far from providing reliable data to support this type of analysis

\section{Corresponding author Juan Oliva}

Department of Economics and Seminar of Social Studies on Health and Medicines, Universidad Carlos III de Madrid, Spain e-mail: juan.oliva@uc3m.es

\section{Acknowledgements}

We thank: A. Blanco and T. Morales (Spanish Ministry of Health and Consumer Affairs); M.D. LópezAbente G. (Carlos III Institute); M.D. Carbajo-Sotillo, A. García-González, J.A. Martínez-Herrera, M. Parrilla-Martín, and M.R. Valero-Muñoz (Social Security Institute); M.L. Muñiz and M.D. Sebastián (Health Department, Region of Madrid), Obdulia Juan Alcaráz (Competitive Techniques), and Natalia Jorgensen (Carlos III University). We are also thankful for the useful comments of Antonio Romero-Medina and Matilde P. Machado (Carlos III University) and those of three anonymous referees. This study was funded by the Spanish Ministry of Health and Consumer Affairs

\section{References}

1. American Cancer Society (2001) Cancer facts and fig ures 2001. American Cancer Society: Atlanta. Available at: www.cancer.org (accessed 3 March 2004)

2. Becker GS (1994) Human capital, 3rd edn. University of Chicago Press: Chicago

3. Boer R, de Koning $H J$, van Oortmarssen GJ, van der Maas PJ (1995) In search of the best upper age limit for breast cancer screening. Eur J Cancer 31A:20402043

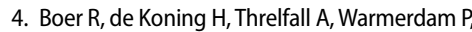
Street A, Friedman E, Woodman C (1998) Cost effectiveness of shortening screening interval or extending age range of NHS breast screening programme: computer simulation study. BMJ 317:376-379

5. Borghouts JA, Koes BW, Vondeling $H$, Bouter LM (1999) Cost-of-illness of neck pain in The Netherlands in 1996. Pain 80:629-636

6. Canadian Coordinating Office for Health Technology Assessment (CCOHTA) (1997) Guidelines for econom ic evaluation of pharmaceutical, 2 nd edn. CCOHTA: Ottawa

7. Grossman M (1972) The demand for health: a theoretical and empirical investigation. Columbia University Press: New York

8. Grossman M (2000) The human capital model of the demand for health. In: Culyer AJ, Newhouse JP (eds) Handbook of health economics. North-Holland: Amsterdam

9. Gyrd-Hansen D, Holund B, Andersen P (1995) A costeffectivenes analysis of cervical cancer screening: health policy implications. Health Policy 34:35-51

10. Hodgson TA, Meiners MR (1982) Cost-of-illness methodology: a guide to assessment practices and procedures. Milbank Q 60:429-491

11. Hutubessy $R C$, van Tulder MW, Vondeling $H$, Bouter LM (1999) Indirect costs of back pain in The Netherlands: a comparison of the human capital method with the friction cost method. Pain 80:201-207

12. Instituto Nacional de Estadística (INE) (2000). Registro de Defunciones por Causa de Muerte. Available at: http://www.ine.es/inebase/menu2.htm8 (accessed 3 March 2004)
13. Instituto Nacional de Estadística (INE) (2000) Encuesta de Salarios en la Industria y los Servicios. Available at: http://www.ine.es/inebase/menu2.htm8 (accessed 3 March 2004)

14. Instituto Nacional de Estadística (INE) (2000) Encuesta de Población Activa. Available at: http://www.ine. es/inebase/menu2.htm8 (accessed 3 March 2004)

15. Johannesson M, Karlsson $G$ (1997) The friction cost method: a comment. J Health Econ 16:249-255

16. Johansson PO (1995) Evaluating health risks: an economic approach. Cambridge University Press: Cambridge

17. Johnson-Thompson MC, Guthrie J (2000) Ongoing research to identify environmental risk factors in breast carcinoma. Cancer 88 [Suppl 5]:1224-1229

18. Koopmanschap MA, van Ineveld BM (1992) Towards a new approach for estimating indirect costs of disease. Soc Sci Med 34:1005-1010

19. Koopmanschap $M A$, Rutten $F F H$, van Ineveld $B M$, van Roijen $L$ (1995) The friction cost method for measuring indirect cost of disease. J Health Econ 14:171-189

20. Leivo T, Sintonen H, Tuominen R, Hakama M, Pukkala E, Heinonen OP (1999) The cost-effectiveness of nationwide breast carcinoma screening in Finland, 1987-1992. Cancer 86:638-646

21. Liljas B (1998) How to calculate indirect costs in economic evaluation. Pharmacoeconomics 13:1-7

22. Lofland JH, Locklear JC, Frick KD (2001) Different approaches to valuing the lost productivity of patients with migraine. Pharmacoeconomics 19:917-925

23. López-Abente $\mathrm{G}$ et al., unpublished

24. Mandelblatt JS, Lawrence WF, Womack SM, Jacobson D, Yi B, Hwang Y et al. (2002) Benefits and cost of using HPV testing to screen for cervical cancer. JAMA 287:2372-2381

25. Marcotte DE, Wilcox-GokV (2001) Estimating the employment and earnings costs of mental illness: recent developments in the United States. Soc Sci Med 53:21-27

26. Max W, Rice DP, Mackenzie EJ (1990) The lifetime cost of injury. Inquiry 27:332-343

27. Max W, Rice DP, Sung HY, Michel M, Breuer W, Zhang $X$ (2003) The economic burden of gynecologic cancers in California, 1998. Gynecol Oncol 88:96-103

28. Mettlin C (1999) Global breast cancer mortality statistics. CA Cancer J Clin 49:138-144

29. Ministerio de Sanidad y Consumo (2003) Plan integral de la cardiopatía isquémica en España. Available at: http://www.msc.es/Diseno/planesIntegrales/planes_integrales.htm (accessed 3 March 2004)

30. Mishan EJ (1990) Cost-benefit analysis: an informal introduction, 4th edn. Unwin Hyman: London

31. Oliva J, Lobo F, López-Bastida J, Duque B, Osuna $R$ (2004) Costes no sanitarios ocasionados por las enfermedades isquémicas del corazón en España. Cuadernos Econ ICE 67:263-298

32. Olsen JA, Smith RD (2001) Theory versus practice: a review of 'willingness-to-pay' in health and health care. Health Econ 10:39-52

33. Robinson JC (1986) Philosophical origins of the economic valuation of life. Milbank Q 64:133-155

34. Thorn TJ (1996) Economic costs of neoplasms, arteriosclerosis, and diabetes in United States. In Vivo $10: 255-260$

35. Tyczynski JE, Bray F, Parkin DM (2002) Breast cancer in Europe. ENCR Cancer Fact Sheets vol 2. Available at: http://www.encr.com.fr/ENCR13.htm (accessed 3 March 2004) 